Bangladesh Journal of Anatomy July 2011, Vol. 9 No. 2 pp 75-78

\title{
Variations in the Shape of the Coronoid Process in the Adult Human Mandible
}

\author{
SM Akram Hossain ${ }^{1}$, SM Moshadeq Hossain², Fakhrul Amin Mohammad Hasanul Banna ${ }^{3}$
}

\begin{abstract}
:
Context: Coronoid process of mandible is of clinically important to maxillofacial surgeons for reconstruction of craniofacial region following trauma, deformities, facial palsy, ankylosis of joints. It also play role as anthropological marker for detection of races. Knowing all the importance the shape of the coronoid processes of both sides of 140 adult human mandibles of which 99 male and 41 female of Bangladeshi origin were studied in order to classify the variations.
\end{abstract}

Study type: Cross-sectional, descriptive type.

Place and period of study: Department of Anatomy, Rajshahi Medical College, Rajshahi and Pabna Medical College, Pabna from March 2010 to June 2011.

Materials and Methods: Total one hundred forty (140) human adult mandibles were collected from the Anatomy department of Rajshahi Medical College, Rajshahi and Pabna Medical College, Pabna in the different times of the study period. The study was conducted to observe the variations in the shapes of the coronoid processes. Then their photographs were taken.

Result: Three types were revealed: 1. hook shaped; 2. triangular and 3. rounded. Hook shaped coronoid processes were found in 126 (45\%), triangular in 83 (29.65\%) and rounded in 71 (25.35\%) sides. Hook shaped coronoid processes were found bilaterally in 56, triangular in 38 and rounded in 30 mandibles. Of the remaining 16 mandibles, the shapes were different on both the sides. The incidence of hook type was almost equal in male and female mandibles, in the triangular type slightly more was found in the female mandibles while the rounded shaped type was more in the male mandibles..

Keywords: Coronoid process, mandible.

Introduction:

The coronoid process of the mandible projects upward and slightly forward as a triangular plate of bone $^{1}$. Its margins and medial surface give attachments to temporalis muscle. The coronoid process is of clinical significance to the maxillofacial surgeons for reconstructive purposes. This study was undertaken to note the form of presentations and their prevalence in dry adult human mandibles.

\section{Materials and Methods:}

The study was conducted on one hundred forty (140) human adult mandibles (280 sides, 198 males and

1. Professor \& Head of the Department of Anatomy, Ad-din Women's Medical College, Dhaka

2. Rajshahi Medical College Hospital, Rajshahi

3. Associate Professor of Anatomy, Ad-din Women's Medical College, Dhaka

Correspondence: Prof. Dr. S. M. Akram Hossain
82 females) of Bangladeshi origin. The mandibles were collected from the Anatomy department of Rajshahi Medical College, Rajshahi and Pabna Medical College, Pabna in the different times of the study period to observe the variation in the shapes of the coronoid processes. The variations of the coronoid processes were observed and their photographs were taken for documentation.

\section{Observation and results:}

Shapes of coronoid processes

There were three types of coronoid process 1 . hook shaped, 2. triangular and 3. rounded shaped (TableI) were observed among the mandibles. The hook shaped coronoid process had a tip which was pointing backwards. This was present in 126 (45\%) sides. It was present bilateral in 56 mandibles (112 sides) while in 14 mandibles (9 right, 5 left) it was 
present unilaterally. Of the 9 right sided mandibles having hook shaped coronoid process, 7 were associated with a rounded and 2 were associated with a triangular coronoid process on the left side. Of the 5 left sided mandibles having hook shaped coronoid process, 3 were associated with a triangular and 2 were associated with a rounded coronoid process on the right side. The triangular coronoid process with a tip pointing straight upward was seen in $83(29.65 \%)$ sides. It was present bilaterally in 38 mandibles (76 sides), while in 7 mandibles (5 right, 2 left), it was found unilaterally. Of the 5 right sided mandibles having triangular coronoid process, 3 were associated with a hook shaped and 2 were associated with a rounded coronoid process on the left side. Of the 2 left sided mandibles having triangular coronoid process, both were associated with a hook shaped coronoid process on the right side. The coronoid process with a rounded tip was present in $71(25.35 \%)$ sides. In 60 mandibles, (120 sides), rounded coronoid process was present bilaterally, while in 11 mandibles (2 right, 9 left), it was found unilaterally. Of the 2 right sided mandibles having rounded coronoid process, both were associated with a triangular coronoid process on the left side. Of the
9 left sided mandibles having rounded coronoid process, 7 were associated with a hook shaped coronoid process and 2 were associated with a triangular coronoid process on the right side.

\section{Distribution of various types in male and female mandibles}

The distribution and incidence of the various types of coronoid process were noted in male and female mandibles (Table - II). Of the 198 sides of mandibles belonging to males, the hook shaped type was found in $89(44.95 \%)$, triangular in $54(27.27 \%)$ and rounded in $55(27.78 \%)$. Of the 82 sides of female mandibles, the hook shaped type was found in 37 (45.12\%), triangular in $29(35.37 \%)$ and rounded in $16(19.51 \%)$.

In this study in $88.57 \%$ mandibles the type of coronoid process was the same bilaterally and only in $11.43 \%$ mandibles did the presentation differ between sides.

The hook shaped and triangular types were the most and the least prevalent in males $(44.95 \%$ and $27.27 \%$ respectively). While in females the hook shaped (45.12\%) and rounded (19.51\%) types were the most and the least prevalent.

Table-I

Distribution of the coronoid process in adult human mandibles (280 sides)

\begin{tabular}{llrrccc}
\hline Type & Shape & \multicolumn{2}{c}{ Number $(\mathrm{n}, \%)$} & Bilateral & \multicolumn{2}{c}{ Unilateral } \\
\hline 1 & Hook & 126, & 45.00 & 112 & 9 & Right \\
2 & Triangular & 83, & 29.65 & 76 & 5 & 2 \\
3 & Rounded & 71, & 25.35 & 60 & 2 & 9 \\
\hline
\end{tabular}

Table - II

Distribution and incidence of the coronoid process in male and female

\begin{tabular}{lcccccc}
\hline Shape & Number $(\mathrm{n})$ & \multicolumn{2}{c}{ Male (198 sides) } & & \multicolumn{2}{c}{ Female ( 82 sides) } \\
& & Bilateral & Unilateral & & Bilateral & Unilateral \\
\hline Hook shaped & 126 & $82(41.41 \%)$ & $7(3.54 \%)$ & & $30(36.59 \%)$ & $7(8.53 \%)$ \\
Triangular & 83 & $52(26.26 \%)$ & $2(1.01 \%)$ & & $24(29.27 \%)$ & $5(6.10 \%)$ \\
Rounded & 71 & $48(24.24 \%)$ & $7(3.54 \%)$ & & $12(14.63 \%)$ & $4(4.88 \%)$ \\
\hline Total & 280 & $182(91.91 \%)$ & $16(8.09 \%)$ & & $66(80.49 \%)$ & $16(19.51 \%)$ \\
\hline
\end{tabular}




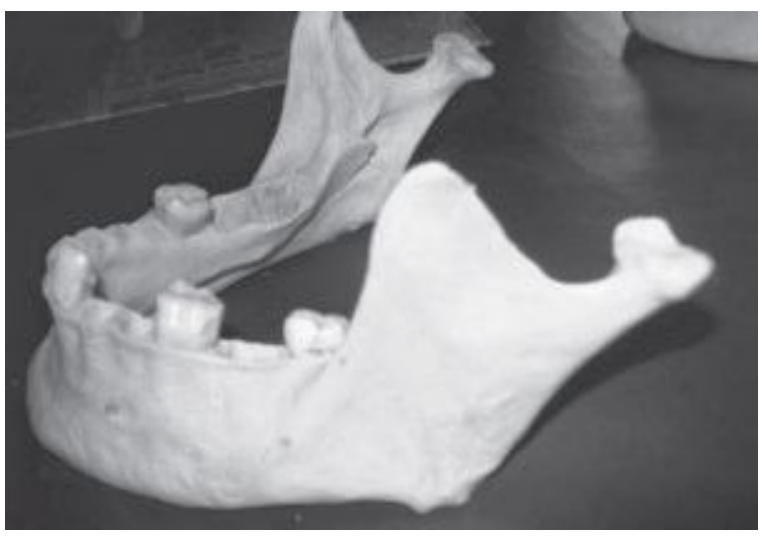

Fig.-1: Hook shaped coronoid process (type-l)

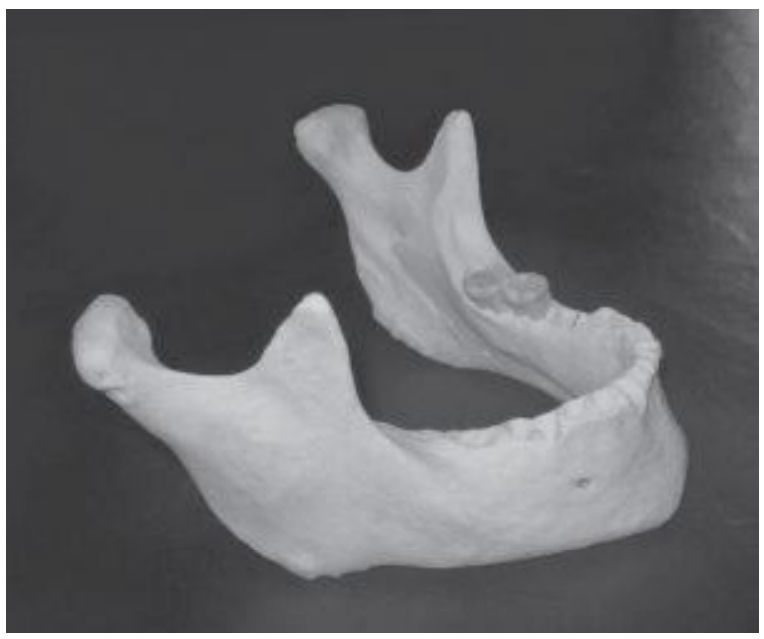

Fig.-2: Triangular coronoid process (type - 2)

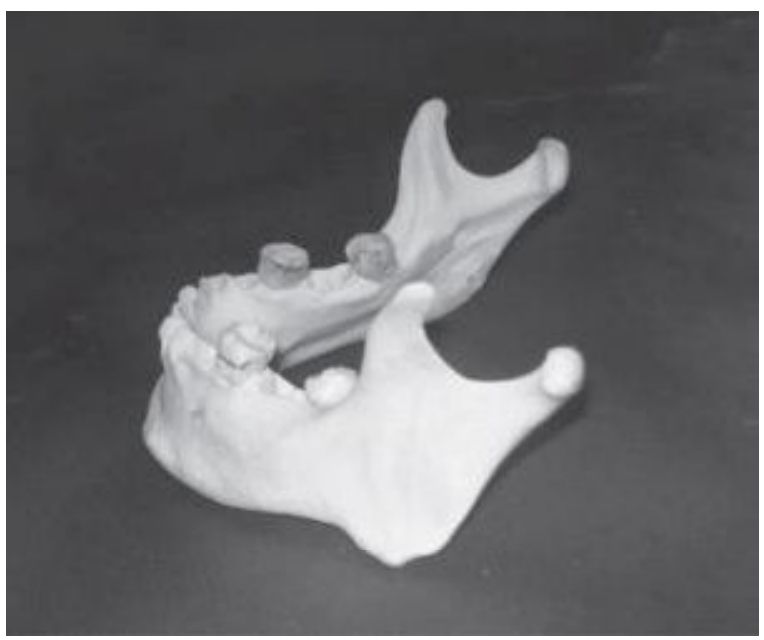

Fig.-3: Rounded coronoid process (type-3)

\section{Discussion:}

The coronoid process, coronoid meaning 'crow' has been described as one of the bony processes of the ramus of the mandible ${ }^{2}$. Standring et al. described the coronoid process as a flat triangular process ${ }^{1}$. Triangular processes have been illustrated by Hamilton ${ }^{3}$, Romanes ${ }^{4}$, Snell ${ }^{5}$ and Basmajian et $\mathrm{al}^{6}$. Schafer et al described the coronoid process as beak-shaped ${ }^{7}$.

Knowledge of the morphological shapes of the coronoid process is useful for the maxillofacial surgeons. The coronoid process makes an excellent donor graft site for reconstruction of orbital floor deformities ${ }^{8}$. Clauser et al. reported the use of a temporalis myofascial flap both as a single and as composite flap with cranial bone, coronoid process or skin island in all aspects of reconstructive craniomaxillofacial surgery including trauma, deformities, tumors, temporomandibular joint ankylosis and facial paralysis ${ }^{9}$.

To our knowledge this is the first study to identify and classify the different morphological shapes of the coronoid process in Bangladeshi mandible. Along with other features of the skull known as nonmetric variants these could be used as anthropological markers to assess different populations and races ${ }^{10}$.

\section{References:}

1. Standring S. Skeletal system. In: William PL, Bannister LH, Barry Mm et al. editors. Gray's Anatomy: The anatomical basis of medicine and surgery. $40^{\text {th }}$ ed. New York, Churchill Livingstone. New York, 2008; p. 532.

2. Field EJ, Harrioson RJ. Anatomical terms: their origin and derivation, $1^{\text {st }}$ ed. Cambridge. W. Heffer \& Sons Ltd. 1947. p. 34.

3. Hamilton WJ. Textbook of Human Anatomy. $2^{\text {nd }}$ ed. London Macmillan. 1976; p. 80.

4. Romanes GJ. Kead and Neck In: Cunningham's manual of Practical Anatomy. $15^{\text {th }}$ ed. Singapore. Oxford University Press; 1986. p. 12. 
5. Snell RS. Head and Neck In: Clinical Anatomy for Medical Students. $3^{\text {rd }}$ ed; Boston: Little Brown and Companyl 1986. p. 773.

6. Basmajian JV, Slonecker CE. Grant's Method of Anatomy. In: $11^{\text {th }}$ ed. Baltimore. London. Williams \& Wilkins; 1989. 516.

7. Schafer EA, Thane GD. Quain's Elements of Anatomy. $10^{\text {th }}$ ed. London: Longmans, green \& Co; 1980; p. 60

8. Mintz SM, Ettinger A, Schmakel T, Gleason MJ. Contralateral coronoid process bone graft for orbital floor reconstruction: an anatomic and clinical study. J Oral Maxillofacial Surg. 1998; 56 (10):1140-5.

9. Clauser L, Curioni C, Spanio S. The use of the temporalis muscle flap in facial and craniofacial reconstructive surgery. A review of 182 cases. J Craniomaxillofacial Surg. 1995; 23(4): 203-14.

10. Berry AC. Factors affecting the incidence of nonmetrical skeletal variants. J Anatomy. 1975; 120: 519-35. 